\title{
Socioeconomic and sex differentials in reason for sickness absence from the Whitehall II study
}

\author{
A Feeney, F North, J Head, R Canner, M Marmot
}

\begin{abstract}
Objectives-Large socioeconomic differences exist in disease and mortality. This paper describes the distribution of specific medical reasons for sickness absence by grade of employment in the Whitehall II study and validates the medical reason by comparison with general practitioners' records.

Methods-Analysis of sickness absence data on 5620 male and female civil servants aged 35-55 years. Data have been collected from 12 of the 20 London based civil service departments participating in the Whitehall II study, where medical reason for absence was available. Rates and distributions of reasons for absence for short spells ( $\leqslant 7$ days) and long spells ( $>7$ days) were analysed.

Results-Respiratory disorders and gastroenteritis accounted for over half of all spells of absence, with headache and migraine, musculoskeletal disorders, injury, and neurosis accounting for a further $20 \%-30 \%$ of absences. There was an inverse association with employment grade, the lower the grade the higher the rate of absence for both short spells $(\leqslant 7$ days) and long spells ( $>7$ days). In general, women had higher rates of absence than men. Comparison of reason for very long spells of absence ( $>21$ days) showed moderate agreement between civil service and general practitioner.
\end{abstract}

Conclusion-There is a lack of national comprehensive data on sickness absence and medical reason for absence, in particular for women and for spells of different duration. Data from the Whitehall II study show large employment grade and sex differences in the distribution of medical reasons for absence that are similar to socioeconomic differences in morbidity documented in other studies. Possible explanations include the subjective nature of illness and disease; the work/family interface; and the influence of the absence culture. Longer term follow up will provide information on whether sickness absence relates to serious morbidity and mortality.

\section{(Occup Environ Med 1998;55:91-98)}

Keywords: sickness absence; sex differences; socioeconomic status

Sickness absence is an important occupational problem with more than 187 million working days lost each year through sickness, with a cost to British business estimated at $£ 12$ billion. ${ }^{1}$ The decision to be absent from work is determined by several social, psychological, and physical factors. Despite the financial costs and loss of productivity, there is no survey in the United Kingdom which provides comprehensive data on sickness absence or medical reasons for absence.

In the Whitehall II study, we have documented differences in rates of sickness absence by sex and employment grade, and have identified factors that contribute to the socioeconomic gradient. ${ }^{2}$ Several other studies have found a similar association between occupational status and sickness absence, ${ }^{3-6}$ and have identified factors contributing to sickness absence. ${ }^{6-11}$ However, few studies have attempted to examine the distribution of reasons for sickness absence by social class or by sex. ${ }^{6}$

Although most companies record information on absence from work, comparisons between organisations are problematic due to the different populations surveyed and the different methods of data collection used. Comparability between studies is often hindered due to the use of poorly defined disease classification systems and an inability to compare reasons for absences for spells of different duration. Also, when data are collected, they are usually recorded for pay purposes so that the reason for absence is generally considered less important.

The opportunity to further investigate sickness absence and in particular, reason for absence, comes from the Whitehall II study, a longitudinal survey of health and disease among 10308 male and female civil servants. As well as a detailed sociomedical examination, information on duration and reason for sickness absence was obtained. In this paper we examine the relation between various sociodemographic factors and reasons for absence for short spells ( $\leqslant 7$ days) and long spells ( $>7$ days). Also, we compare the civil service reason for very long spells of absence ( $>21$ days) with further diagnostic information provided by the general practitioner (GP).

\section{Method}

All non-industrial civil servants aged 35-55 working in the London offices of 20 departments were invited to participate in the study. The overall response rate was $73 \%$ ( $74 \%$ for men and $71 \%$ for women). The true response rates are likely to be higher because around $4 \%$ of those on the list of employees had moved before the study and were thus not eligible for inclusion. As previously reported, there were 
differences in response rate by grade of employment, particularly for men. ${ }^{12}$ In total, 10308 civil servants participated, of whom $66.9 \%$ (6895) were men and 33.1\% (3413) were women. Between September 1985 and March 1988, participants completed questionnaires and attended a screening examination; the details of data collected have been reported elsewhere. ${ }^{12}$

\section{GRADE OF EMPLOYMENT}

Information on grade of employment was obtained by asking all participants to give their civil service grade title. On the basis of salary, the civil service identifies 12 non-industrial grades, which, in order of decreasing salary, comprise seven unified grades, senior executive officer (SEO), higher executive officer (HEO), executive officer (EO), clerical officer, clerical assistant, and office support staff. Other professional and technical staff are assigned by the civil service to one of these grades on the basis of salary. There was a steep increment in salaries between grade categories-from an annual salary in 1987 of $£ 3061-£ 5841$ in the clerical and office support grades to $£ 18020$ $£ 62100$ in the unified grades $1-6$. There were also considerable differences in other socioeconomic indicators (education, housing tenure, car ownership, and father's occupation) by grade of employment and these have been described elsewhere. ${ }^{12}$ For analysis, we have combined unified grades 1-7 into one group (administrative), the executive grades into a second group (executive/professional), and the clerical and office support staff into a third group (clerical/office support).

SICKNESS ABSENCE RECORDS

At the time of screening, participants' consent was sought to monitor their sickness absence record and to write to their GPs for further details on absences. A total of 93\% (9564) of participants gave consent and of these 96\% (9179) were linked with their record. Computerised sickness absence records were obtained annually from civil service payroll centres. Reason for absence was recorded in 12 of the 20 departments participating in the Whitehall II study, and thus, was available for $61 \%$ (5626) of participants linked with their records. Reason for absence was not available for $39 \%$ (3553) of participants as they were based in departments with payroll centres which did not record reason for absence. Absence for maternity leave was excluded from analyses. The sickness absence policy in the civil service at the time of data collection was as follows: for absences of seven days or less, civil servants were able to complete their own certificate explaining the reason for absence; for absences longer than seven days, the GP had to complete a medical certificate. If employees were absent for more than 14 self certified days a year or more than 90 days in total over two years, they were referred to the Occupational Health Service for assessment. All employees received full pay during a period of absence up to six months in any 12 months. Absences for social reasons (for example, look- ing after dependent relatives, or general medical appointments) were permitted if the absence was accompanied by a medical certificate, but the policy was less clear for short spells and relied on participants providing this information on the certificates.

REASON FOR ABSENCE

From the baseline screening in 1985 to the end of 1990 there were 29419 spells of sickness absence among the 5626 participants working in departments where reason for absence was coded. Detailed information on reason for absence was available for $94 \%$ (27 663) of these spells. The reason for absence was coded by the civil service with a four digit code based on the $\mathrm{C}$ list of the eighth revision of the international classification of diseases (ICD-8). ${ }^{13}$ For the purpose of analyses the codes were converted to disease categories with the morbidity coding system of the Royal College of General Practitioners (RCGPs), ${ }^{14}$ which is comparable with the ICD-8. Not all civil service reason codes were present in the RCGP classification: of the 427 civil service codes, $75 \%$ were identified in the RCGP classification and converted to the appropriate disease category. The remaining $25 \%$ of civil service codes were allocated to similar but not identical disease categories. For example, the civil service reason "gastric infection" was not present in the RCGP classification but was classified alongside similar reasons in the disease category "infectious and parasitic diseases". The disease category "symptoms, signs, and ill defined conditions" consisted mainly of investigations, treatments, and symptoms not classified elsewhere.

\section{MODIFICATION OF RCGP CLASSIFICATION}

The morbidity coding system was modified with the addition of four new disease categories. The extra categories were formed as it was thought that some reasons responsible for a high proportion of short absences were inappropriately classified under the original RCGP system. For example, in the RCGP system "headaches" were classified under symptoms, signs, and ill defined conditions; "migraines" under diseases of nervous system; "diarrhoea and vomiting" under infections and parasitic diseases; and various stress related conditions were classified under mental diseases and symptoms, signs, and ill defined conditions. Four new disease categories were created to take account of these modifications: (a) gastroenteritis; (b) headache and migraine; (c) neurosis; and (d) neurosis ill defined (table 1). Conditions for which there was a clear cut diagnosis of minor psychiatric disorder-for example, neurotic depression, anxiety state, phobia-were included in neurosis. Where the terminology was vague or ambiguous they were classified as neurosis ill defined-for example, emotional upset, nervous breakdown, and nervous trouble. 
Table 1 Disease classification of reasons for absence (from the Royal College of General Practitioners' classification)

\begin{tabular}{cl}
\hline Disease code & Disease categories \\
\hline 1 & Infections and parasitic diseases \\
& Gastroenteritis \\
2 & Neoplasms \\
3 & Endocrine, nutritional, and metabolic diseases \\
4 & Diseases of blood and blood forming organs \\
5 & Psychoses (previously mental) \\
& Neurosis \\
& Neurosis ill defined \\
6 & Diseases of nervous system \\
& Migraine \\
7 & Diseases of eye \\
8 & Diseases of ear \\
9 & Cardiovascular diseases \\
10 & Cerebrovascular diseases \\
11 & Peripheral vascular diseases \\
12 & Diseases of respiratory system \\
13 & Diseases of digestive system \\
14 & Diseases of genitourinary system \\
15 & Complications of pregnancy, childbirth, and \\
& puerperium \\
16 & Diseases of skin and subcutaneous tissue \\
17 & Diseases of musculoskeletal system and \\
& connective tissue \\
20 & Symptoms, signs, and ill defined conditions \\
23 & Headache \\
32 & Injury and poisoning \\
37 & General medical examinations and screening \\
& Surgical operations \\
$\star$ &
\end{tabular}

^ New disease categories created.

RELIABILITY OF REASONS FOR SICKNESS ABSENCE RECORDS

The absence records are primarily used for pay purposes by the civil service. It is therefore possible that the civil service reasons for absence may be less accurate than the dates of absence. To assess the accuracy of the data on reason for absence, participants' GPs were asked to provide further information for all very long spells ( $>21$ days) that occurred from 1985-90. A total of 1647 questionnaires were posted, each indicating when the participant's absence had occurred. General practitioners were asked to specify the reason for absence and to provide copies of hospital discharge letters and summaries of investigations if available. This enabled us to assess the accuracy of reasons for absence as well as obtaining further diagnostic information. Overall $92 \%$ of GPs responded after three letters and a telephone reminder. Most ( $81 \%$ ) of the GPs provided further information. Reasons for not providing information were GP refused ( $4 \%$ ); no record of absence (3\%); participant had left practice without trace $(3 \%)$; and participant had died $(1 \%)$.

Table 2 Agreement between civil service and general practitioner classifications for specific diagnosis and disease category when GP provided one, or more, reason for absences $>21$ days

\begin{tabular}{lcccc}
\hline Civil service disease category & $\begin{array}{l}\text { Agree specific } \\
\text { diagnosis }\end{array}$ & $\begin{array}{l}\text { Agree disease } \\
\text { category }\end{array}$ & Disagree & Total \\
\hline One reason: & $40(42)$ & $38(40)$ & $17(18)$ & 95 \\
$\quad$ Mental & $32(49)$ & $21(32)$ & $12(19)$ & 65 \\
Musculoskeletal & $17(40)$ & $10(24)$ & $15(36)$ & 42 \\
Respiratory & $5(42)$ & $1(8)$ & $6(50)$ & 12 \\
Cardiovascular & $94(44)$ & $70(33)$ & $50(23)$ & 214 \\
$\quad$ Total & $11(44)$ & $12(48)$ & $2(8)$ & 25 \\
More than one reason: & $14(70)$ & $5(25)$ & $1(5)$ & 20 \\
Mental & $9(53)$ & $6(35)$ & $2(12)$ & 17 \\
Musculoskeletal & $12(67)$ & $3(16)$ & $3(16)$ & 18 \\
Respiratory & $46(58)$ & $26(32)$ & $8(10)$ & 80 \\
Cardiovascular & & & & \\
Total & & &
\end{tabular}

Values are $n(\%)$.
The GPs could specify in their follow up questionnaire more than one reason for absence. Consequently we examined agreement between civil service records and information provided by the GP for four main disease categories where $(a)$ the GP provided one reason and $(b)$ the GP provided several reasons for absence (table 2).

\section{STATISTICAL ANALYSIS}

Short spells ( $\leqslant 7$ days) and long spells ( $>7$ days) of sickness absence were analysed separately. For each person, the number of spells of sickness absence of each type were computed and the follow up period was measured in person-years. Age adjusted rates of spells of sickness absence were calculated for men and women separately, by direct standardisation, with the total sample as standard, and these rates are expressed per 100 personyears.

The trend in rates of sickness absence across employment grade was tested for significance by fitting a Poisson regression model to the data and including age and a linear term for grade. Further details of this method are given elsewhere. $^{2}$

The distribution of reasons for absence and agreement between the civil service and general practitioner are expressed as percentages.

\section{Results}

RELIABILITY OF REASONS FOR ABSENCE

To evaluate the reliability of the civil service records, the civil service reason for very long spells of absence ( $>$ 21days) was compared with further diagnostic information from the GP (All absences $>21$ days regardless of whether they had a reason coded by the civil service were posted to GPs for further information. Comparison of reasons for absence was only possible when both a civil service and GP reason were available. Comparison was therefore made on 664 absences in which both a civil service and GP reason were available.) Agreement was examined at two levels: (a) the specific reason; and $(b)$ the disease category. Overall, there was agreement on $64 \%$ (95\% confidence interval $(95 \% \mathrm{CI})$ $60 \%$ to $68 \%$ ) of absences between the civil service and GP, with agreement on specific reason for $36 \%$ and agreement on disease category (but not specific reason) for $28 \%$ of absences.

Table 2 shows agreement rates between the civil service and GP for four main disease categories. In general, the agreement was higher when the GP provided more than one reason, with a total agreement of $77 \%$ for one reason compared with a total agreement of $90 \%$ when more than one reason was provided (table 2).

There were several possible explanations for the disagreement on reason for absence between the civil service records and GPs, diagnostic information: (a) the civil service may have coded the reason for absence on the certificate incorrectly; (b) the GP may have recorded one reason on the certificate and a different reason in the notes; and (c) the GP 
Table 3 Age adjusted rates * and \% of reasons for sickness absence by sex

\begin{tabular}{|c|c|c|c|c|c|c|}
\hline \multirow[b]{2}{*}{ Reason } & \multicolumn{3}{|c|}{ Men $(n=3932)$} & \multicolumn{3}{|c|}{ Women $(n=1694)$} \\
\hline & Spells (n) & $\%$ & Rate* & Spells (n) & $\%$ & Rate $^{\star}$ \\
\hline Respiratory & 7059 & 44.5 & 52.4 & 4599 & 39.0 & 78.9 \\
\hline Gastroenteritis & 2457 & 15.5 & 18.3 & 1589 & 13.5 & 27.3 \\
\hline Headaches/migraine & 965 & 6.1 & 7.1 & 1200 & 10.2 & 20.4 \\
\hline Musculoskeletal & 996 & 6.3 & 7.4 & 767 & 6.5 & 12.7 \\
\hline Injury & 866 & 5.5 & 6.4 & 595 & 5.0 & 10.0 \\
\hline Neurosis ill defined & 581 & 3.7 & 4.3 & 647 & 5.5 & 11.0 \\
\hline Surgery & 392 & 2.5 & 2.9 & 324 & 2.8 & 5.5 \\
\hline Digestive & 396 & 2.5 & 2.9 & 221 & 1.9 & 3.8 \\
\hline Ill defined conditions & 313 & 2.0 & 2.3 & 229 & 1.9 & 3.9 \\
\hline Genitourinary & 76 & 0.5 & 0.6 & 262 & 2.2 & 4.6 \\
\hline Neurosis & 102 & 0.6 & 0.8 & 106 & 0.9 & 1.8 \\
\hline Cardiovascular & 68 & 0.4 & 0.5 & 63 & 0.5 & 1.0 \\
\hline Other & 1594 & 10.0 & 11.8 & 1196 & 10.1 & 20.5 \\
\hline Total & 15865 & 100 & 117.7 & 11798 & 100 & 201.5 \\
\hline
\end{tabular}

$\star$ Age adjusted rates of absence $/ 100$ person-years.

Reason for absence provided by civil service ( $n=27663$ spells).

may have provided us with incorrect information. We were unable to investigate explanations $(a)$ and $(b)$ as it was not feasible to go back to the civil service to check on the accuracy of the certificates. We were, however, able to estimate how much explanation (c) may have contributed to the proportion where there was disagreement.

For those absences where there was disagreement $(n=242)$, a research assistant visited a sample of the practices to verify from the medical records the diagnostic information given to us by the GP. Forty three practices were visited; this represented $18 \%$ of absence disagreements. Both the GP and civil service reasons were correct in 14 cases $(33 \%)$ as the absences were for multiple reasons. The errors in the remaining 29 cases were evenly divided between information provided by the GPs and reason for absence recorded by the civil service.

\section{REASON FOR ABSENCE}

Respiratory disorders and gastroenteritis accounted for between $50 \%-60 \%$ of all spells of absence, with headache and migraine, musculoskeletal disorders, injury, and neurosis ill defined accounting for a further $20 \%-30 \%$ of absences. The proportion of absences due to specific disease categories was similar for men and women. However, across all disease categories, women had higher rates of absence than men (table 3). All subsequent results will therefore focus on rates of absence.
REASON FOR ABSENCE BY EMPLOYMENT GRADE In this analysis we grouped the employment grades into three employment groups: (a) administrative, (b) professional/executive, and (c) clerical and office support. In general there was a striking inverse association with employment grade, the lower the grade the higher the rate of absence. Within employment grade, women had generally higher rates of absence than men, with the exception of short spells in the clerical and office support group where men had higher rates than women.

For short spells ( $\leqslant 7$ days), the grade differential was particularly high for gastroenteritis, headache and migraine, neurosis ill defined, musculoskeletal, injury, ill defined conditions (mainly treatment and investigations), and digestive disorders, and for women genitourinary disorders, with rates four to 16 times higher for these disease categories in the lower clerical/office support group (table 4). For long spells ( $>7$ days) the gradient was most obvious for musculoskeletal and respiratory disorders, injury, and neuroses, and for women genitourinary disorders (table 5).

For cardiovascular disorders there was a gradient for men but not women, with men in the lower employment groups having up to nine times higher rates for short and long spells. Interestingly, for women there was a slight but non-significant gradient in the opposite direction with higher rates of cardiovascular disorders in the higher employment

Table 4 Age adjusted rates ${ }^{\star}$ of reasons for short spells of sickness absence ( $\leqslant 7$ days) by employment grade

\begin{tabular}{|c|c|c|c|c|c|c|c|c|}
\hline \multirow[b]{2}{*}{ Reason } & \multicolumn{4}{|l|}{$\operatorname{Men}(n=3932)$} & \multicolumn{4}{|c|}{ Women $(n=1694)$} \\
\hline & Administrative & Executive & Clerical & $p$ Valuet & Administrative & Executive & Clerical & $p$ Valuet \\
\hline Respiratory & 31.5 & 58.4 & 93.7 & $<0.0001$ & 34.6 & 72.4 & 81.3 & $<0.0001$ \\
\hline Gastroenteritis & 8.1 & 20.9 & 53.1 & $<0.0001$ & 8.2 & 24.4 & 36.2 & $<0.0001$ \\
\hline Headache/migraine & 3.1 & 8.5 & 21.7 & $<0.0001$ & 6.4 & 21.0 & 24.9 & $<0.0001$ \\
\hline Musculoskeletal & 3.0 & 7.1 & 17.6 & $<0.0001$ & 0.8 & 7.1 & 16.7 & $<0.0001$ \\
\hline Injury & 3.2 & 5.9 & 13.8 & $<0.0001$ & 2.0 & 7.6 & 10.3 & $<0.0001$ \\
\hline Neurosis ill defined & 2.0 & 4.1 & 10.8 & $<0.0001$ & 2.8 & 7.9 & 12.5 & $<0.0001$ \\
\hline Surgery & 1.0 & 2.0 & 2.2 & $<0.0001$ & 0.9 & 2.5 & 2.5 & 0.046 \\
\hline Digestive & 1.1 & 3.2 & 8.3 & $<0.0001$ & 1.1 & 3.8 & 4.0 & 0.008 \\
\hline Ill defined conditions & 1.2 & 1.6 & 12.1 & $<0.0001$ & 1.2 & 3.3 & 3.8 & 0.003 \\
\hline Genitourinary & 0.3 & 0.7 & 0.3 & 0.03 & 0.5 & 3.6 & 6.1 & $<0.0001$ \\
\hline Neurosis & 0.3 & 0.3 & 0.4 & 0.32 & 0.0 & 0.6 & 0.8 & 0.025 \\
\hline Cardiovascular & 0.1 & 0.3 & 1.0 & $<0.0001$ & 1.3 & 0.3 & 0.9 & 0.32 \\
\hline Other & 6.8 & 11.2 & 17.5 & $<0.0001$ & 8.0 & 17.1 & 17.9 & $<0.0001$ \\
\hline Total (with reason) & 61.7 & 123.9 & 252.5 & & 67.7 & 171.6 & 217.9 & \\
\hline
\end{tabular}

*Age adjusted rates of absence/100 person-years.

$\dagger$ Test for trend. Reason for absence provided by civil service ( $n=24644$ spells). 
Table 5 Age adjusted rates ${ }^{\star}$ of reasons for long spells of sickness absence (> 7 days) by employment grade

\begin{tabular}{|c|c|c|c|c|c|c|c|c|}
\hline \multirow[b]{2}{*}{ Reason } & \multicolumn{4}{|l|}{$\operatorname{Men}(n=3932)$} & \multicolumn{4}{|c|}{ Women $(n=1694)$} \\
\hline & Administrative & Executive & Clerical & $p$ Valuet & Administrative & Executive & Clerical & $p$ Valuet \\
\hline Respiratory & 1.3 & 3.1 & 7.0 & $<0.0001$ & 3.4 & 7.7 & 12.2 & $<0.0001$ \\
\hline Gastroenteritis & 0.2 & 0.2 & 0.8 & 0.05 & 0.2 & 0.5 & 0.9 & 0.01 \\
\hline Headache/migraine & 0.03 & 0.1 & 0.2 & 0.08 & 0.0 & 0.04 & 0.4 & 0.0047 \\
\hline Musculoskeletal & 0.8 & 1.4 & 4.0 & $<0.0001$ & 0.5 & 1.8 & 4.2 & $<0.0001$ \\
\hline Injury & 0.5 & 1.3 & 2.5 & $<0.0001$ & 0.5 & 1.4 & 3.5 & $<0.0001$ \\
\hline Neurosis ill defined & 0.5 & 0.7 & 1.6 & 0.0009 & 0.4 & 1.5 & 3.0 & $<0.0001$ \\
\hline Surgery & 1.2 & 1.3 & 1.1 & 0.84 & 1.1 & 2.9 & 4.3 & $<0.0001$ \\
\hline Digestive & 0.1 & 0.3 & 1.8 & $<0.0001$ & 0.2 & 0.6 & 0.3 & 0.72 \\
\hline Ill defined conditions & 0.3 & 0.2 & 0.2 & 0.32 & 0.2 & 0.7 & 1.0 & 0.01 \\
\hline Genitourinary & 0.1 & 0.1 & 0.1 & 0.75 & 0.1 & 0.5 & 1.0 & 0.0027 \\
\hline Neurosis & 0.4 & 0.4 & 1.8 & $<0.0001$ & 0.4 & 1.0 & 1.8 & 0.0047 \\
\hline Cardiovascular & 0.03 & 0.3 & 1.1 & $<0.0001$ & 0.4 & 0.4 & 0.2 & 0.32 \\
\hline Other & 0.9 & 2.4 & 3.4 & $<0.0001$ & 1.9 & 3.4 & 5.4 & $<0.0001$ \\
\hline Total & 6.2 & 11.6 & 25.5 & & 9.1 & 22.4 & 38.3 & \\
\hline
\end{tabular}

* Age adjusted rates of absence per 100 person years.

$\dagger$ Test for trend. Reason for absence provided by civil service $(n=3019$ spells $)$.

groups, although the numbers in this disease category were small.

REASON FOR ABSENCE BY SEX

Table 6 shows rate ratios compared for different disease categories controlling for the effects of age and employment grade. For short spells ( $\leqslant 7$ days) there were some disease categories where men had an excess ratenotably, gastroenteritis, musculoskeletal and digestive disorders, and ill defined conditions; and for long spells ( $>7$ days) men had an excess rate for headache and migraine, and digestive and cardiovascular disorders, although the difference between men and women was not significant. However, after controlling for employment grade women still had particularly high rates for some disease categories, notably for short spells, in which women had twice the rate of absence for headache and migraine and six times higher rate for genitourinary disorders; and for long spells, where women had two to four times higher rates of respiratory disorders, surgery, ill defined conditions, and genitourinary disorders.

\section{Discussion}

Sickness absence imposes considerable direct and indirect costs on the employer, yet despite these costs, there is no survey in the United Kingdom which provides comprehensive data on sickness absence or the medical reasons for absence. The general household survey used to collect information on reasons for absence classified into four general categories. However, since 1984 this source of information has been omitted, and the general household

Table 6 Age and grade adjusted rate ratios for reasons for absence (women $v$ men (95\% CI))

\begin{tabular}{lll}
\hline Reason & Short spells ( $\leqslant 7$ days) & Long spells ( $>7$ days) \\
\hline Respiratory & $1.11(1.06$ to 1.16$)$ & $2.19(1.88$ to 2.55$)$ \\
Gastroenteritis & $0.93(0.87$ to 1.01$)$ & $1.49(0.87$ to 2.53$)$ \\
Headache/migraine & $2.00(1.82$ to 2.21$)$ & $0.79(0.27$ to 2.27$)$ \\
Musculoskeletal & $0.90(0.79$ to 1.01$)$ & $1.11(0.86$ to 1.43$)$ \\
Injury & $0.99(0.87$ to 1.14$)$ & $1.21(0.91$ to 1.59$)$ \\
Neurosis ill defined & $1.56(1.36$ to 1.80$)$ & $1.99(1.44$ to 2.75$)$ \\
Surgery & $1.16(0.91$ to 1.48$)$ & $2.11(1.66$ to 2.67$)$ \\
Digestive & $0.83(0.68$ to 1.02$)$ & $0.82(0.45$ to 1.48$)$ \\
Ill defined conditions & $0.73(0.59$ to 0.91$)$ & $2.89(1.66$ to 5.03$)$ \\
Genitourinary & $5.87(4.34$ to 7.94$)$ & $4.09(2.00$ to 8.37$)$ \\
Neurosis & $1.65(0.97$ to 2.80$)$ & $1.55(1.04$ to 2.30$)$ \\
Cardiovascular & $1.86(1.08$ to 3.20$)$ & $0.66(0.34$ to 1.25$)$ \\
\hline
\end{tabular}

survey now only asks about longstanding illnesses and restricted activity during the previous 14 days. ${ }^{15}$ In the Whitehall II study we were able to compare the distribution of reasons for absence for short ( $\leqslant 7$ days) and long (> 7 days) spells for men and women in different grades of employment.

ACCURACY OF MEDICAL CERTIFICATES

The accuracy of a medical certificate depends on the ability of the general practitioner to determine when a person must stop work because of illness or injury and when she or he may go back to work. Many of the most common illnesses have few, if any objective signs - for example. backache and minor psychiatric disorders. It is therefore difficult to diagnose these conditions with certainty and to determine the extent to which ability to work is impaired. It is interesting to note that in the Whitehall II study, these common illnesses made the greatest contribution to the grade differentials in sickness absence.

It is beyond the scope of the study to investigate objective ways of judging a person's ability to work. However, we were able to compare reasons for absence in the civil service records with further information provided by the participants' GPs for further information. There was overall agreement on $64 \%$ of absences between the civil service and GP, with agreement on specific reason for $36 \%$ and agreement on disease category (but not specific reason) for $28 \%$ of absences. This type of comparison is rarely carried out, but studies which have looked at these comparisons have reported agreement between certificate and illness recorded, especially if broad diagnostic groups are used. ${ }^{7}$ Also, we found that agreement was higher if the GP provided more than one reason for absence, suggesting that absences are often due to multiple reasons and therefore follow up to GPs should allow for disclosure of more than one reason.

We visited a sample of the practices $(18 \%)$ in which there was disagreement between the civil service and GP and found that a third of the absences were due to multiple causes. The disagreement had arisen because only one reason for absence could be recorded by the civil service. The remaining disagreement was 
equally divided between the civil service and GPs. Possible reasons for the disagreement include: the time delay in contacting GPs for further information on absences that occurred up to four years previously; and GPs having to rely on records they may not have completed at the time of the absence. The national morbidity survey ${ }^{16}$ asked GPs how confident they were with their diagnosis made at a consultation, this varied between $12 \%-89 \%$. It is often difficult to make a confident diagnosis at a first consultation especially if there are vague/subjective symptoms, with hindsight a diagnosis may become more evident. Haland Haldorsen et $a l^{17}$ found a lack of consensus among GPs on whether to issue a sickness certificate when faced with subjective complaints, particularly musculoskeletal pain, psychiatric disorders, and social cases. They suggest that a decision criteria for GPs should be identified and implemented to enable GPs to reach a consensus on issuing sickness certificates when faced with vague and subjective complaints. Errors occurring at the coding stage within the civil service and in the GP notes may also have contributed to the disagreement.

REASONS FOR ABSENCE

Overall, the most frequent reasons on certificates were respiratory disorders and gastroenteritis, with absences for these two disease categories accounting for $50 \%-60 \%$ of all spells. The importance of other reasons for absence differed by duration of spell with respiratory disorders, headache and migraine, and gastroenteritis being more frequent for short spells; and surgery, neurosis, and musculoskeletal and respiratory disorders being more frequent for long spells of absence. These reasons are similar to those found in other studies, ${ }^{36-818}$ although not all of these studies classified reason for absence by sex, or by duration. Short spells of $\leqslant 7$ days were self certificated so it is difficult to assess the accuracy of the reasons reported. In this analysis, most short spells for gastroenteritis were due to stomach upset, and most short spells for respiratory disorders were due to colds and flu. Respiratory disorders continued to be a common reason for longer absences, whereas gastroenteritis and headache and migraine were more important for short spells. The Industrial Society ${ }^{19}$ in a survey of absence from work in 592 organisations asked employers what they considered to be the true reasons for absence; absences reported as colds and flu were thought to be genuine, whereas absences reported as stomach upset were thought to be a cover for emotional or personal problems or stress. Kristensen ${ }^{10}$ in a study of Danish slaughterhouse workers identified job strain and sex as the two most important factors for high rates of sickness absence, and a recent survey by MIND reported that the work environment had replaced the home as the principle focus for stress. ${ }^{20}$ Employees may well be using short spells of absence as a coping strategy to enable them to deal with stressful roles both at work and at home. ${ }^{1020}$
GRADE DIFFERENCES IN REASONS FOR ABSENCE Several studies have found an association between employment status and ill health with reports of higher rates of sickness absence among less skilled non-manual and manual employees. ${ }^{2-6}$ In the Whitehall II study there was a steep grade gradient in rates of both short and long absences with higher rates in the lower employment grades. ${ }^{2}$ Although socioeconomic differences have been documented in sickness absence, few studies have looked at the distribution of reasons for absence by sex or by social class.

The largest grade differences for men were for respiratory disorders, gastroenteritis, headaches and migraine, musculoskeletal and digestive disorders, and ill defined conditions, and for women musculoskeletal disorders, neurosis ill defined, and genitourinary disorders. Similar socioeconomic differences have been documented for other measures of morbidity. The national morbidity survey found that the proportion of patients consulting their GP increased from social classes I to IV, and that the differences were greater for patients consulting for diseases and conditions categorised as serious rather than trivial. ${ }^{21}$ The general household survey also found a similar gradient for both men and women reporting longstanding illness and limiting longstanding illness between manual and non-manual socioeconomic groups. The four most often reported longstanding conditions were disorders of the musculoskeletal, circulatory, respiratory, and digestive systems and all showed an inverse gradient by socioeconomic status. ${ }^{15}$ The health and lifestyle survey also reported that there were clear differences between non-manual and manual occupational groups which applied to several measures of ill health as well as several types of conditions. ${ }^{22}$

It is interesting to note that the employment gradient in sickness absence identified by North et $a l^{2}$ is replicated and even more pronounced for certain reasons for absence.

The influence of the absence culture needs to be considered when interpreting the grade differences in reasons for absence. ${ }^{23}$ Anecdotal evidence suggests that managers and professionals are more likely to be absent from work without record than employees with lower status. This may, in some part, explain the gradient for short spells of absence among the higher grades, but it is unlikely to explain the gradient in lower grades and for long spells that require a medical certificate. Attitudes about acceptable levels of sickness absence may also differ by grade of employment and sex, but this is less likely to contribute to the gradient in long spells. Certain reasons for absence may also be more acceptable in certain employment grades and for women more than men.

\section{SEX DIFFERENCES IN REASONS FOR ABSENCE}

Taking account of employment grade, women generally had higher rates of both short and long spells of absence. This is consistent with other studies comparing sickness absence in men and women ${ }^{610}{ }^{11}$ and with publications on sex differences in reported morbidity. ${ }^{24-26}$ The 
current debate is whether the sex difference is social, psychological, or genetic in origin, with hypotheses emphasising risks from roles and stresses, attitudes underlying symptom perception, health actions, and the reporting of health problems. $^{24}$ One of many hypotheses put forward to explain women's higher morbidity has focused on the fact that the comparisons of health have often been made between different populations: men and women in different work settings; or between men in paid employment and women at home. Consequently the potential confounding effects of employment status or roles at home have been neglected. A particular strength of the Whitehall II study is the homogeneity of the sample and the ability to compare men and women in similar employment grades. Overall women tended to have higher rates of reasons for absence when comparing men and women in similar grades. This is consistent with studies which report a higher rate of minor morbidity among women, whereas men have higher rates of more serious morbidity and mortality. ${ }^{24-27}$

The reporting of higher levels of morbidity in women may be a consequence of their position within the employment grade structure. In the Whitehall II study, $50 \%$ of women were employed in the clerical and office support grades compared with $9 \%$ of men. Comparing rate ratios for reasons for absence adjusted for employment grade showed that there were several disease categories in which men tended to have an excess-notably, gastroenteritis, musculoskeletal and digestive disorders, and ill defined conditions for short spells, headache and migraine, and digestive and cardiovascular disorders for long spells. These results suggest that the pattern of sex differences in morbidity may not always be in the direction of a female excess, but may be dependent on the specific symptoms or conditions under study. ${ }^{28}$

Women still tended to have higher rates of absence for some disease categories after adjustment for grade, notably for short spells, headaches and migraines, neurosis, and cardiovascular and genitourinary disorders, in which rates were two to five times higher than in men. Similarly, for long spells women had particularly high rates of absence for respiratory disorders, neurosis, surgery, ill defined conditions, and genitourinary disorders with rates two to three times higher than in men. Few studies have documented reason for absence by sex and social class, but in those that have, similar results have been found. ${ }^{6}$

It has been suggested that the largest sex difference in disease categories for which men and women seek medical care are those which represent mild morbidity and those in which there is more discretion in defining illness or the need for care, the differences being due to the way symptoms are perceived, evaluated, and acted on. ${ }^{25}$ It may also be that the health effects of the work/family interface are greater for women, resulting in women experiencing more minor subjective illnesses. Alternatively the work/family interface may be the actual reason for the absence, but a subjective medical reason may be given because it is considered more acceptable. This could be consistent with women's greater reporting of absence for headache and migraine, neurosis, and ill defined conditions, but it does not explain the higher rates of long spells for respiratory disorders and surgery. The increase in short absences for cardiovascular disorders was mainly due to absences for chest pain and hypertension. This is likely to be related to women's excess reporting of angina found at the screening examination. ${ }^{12}$ Also, women's greater use of health services means that they are more likely to be screened and therefore, possibly identified and treated for hypertension. Haynes et a ${ }^{29}$ found that regardless of whether antihypertensive treatment was begun, labelling of patients as hypertensive resulted in increased absenteeism from work. Use of health services and labelling of disease are obviously important explanations for sex differences in sickness absence. We have not been able to consider these issues in this analysis, but they will be pursued in our longitudinal analyses, together with the work/family interface and multiple roles as possible explanatory factors to explain sex differences in health.

\section{MORBIDITY AND MORTALITY}

Martikainen $^{30}$ in a prospective study of mortality in Finland, found that mortality increased as the number of sick days increased. The Whitehall II study has been using sickness absence data as a general measure of morbidity because of its strong association with measures of ill health taken at the baseline examination. ${ }^{31}$ Can sickness absence in the Whitehall II study therefore, be used as a useful predictor of serious morbidity and mortality? The main causes of mortality for men and women are from cardiovascular and respiratory diseases and cancers. ${ }^{32}$ Morbidity from certain causes-for example, cancers - is often underreported and is often coded as chronic illness. ${ }^{33}$ The rates of absences for these reasons were small in this analysis, presumably because of the age of the cohort, although respiratory disorders were found to be a main cause of both short and long spells of absence. The most common causes of medical retirement in the civil service are for cardiovascular and mental disorders. ${ }^{3}$ Recent statistics from the Department of Social Security on $1 \%$ of those claiming sickness and invalidity benefit show that ischaemic heart disease, musculoskeletal disorders, and mental illnesses are the main causes of disease for those claiming benefit. ${ }^{34}$ Our data show that musculoskeletal and mental disorders are among the main reasons for long spells of absence for both men and women. Clearly as we collect more data and the age of the study population increases, we will be able to examine whether sickness absence for particular disease categories predicts subsequent serious morbidity and mortality.

REPRESENTATIVENESS OF THE SAMPLE

The analysis was based on $61 \%$ of participants. The remaining $39 \%$ of participants were based in departments with payroll centres that did not record reason for absence. The percentage 
of missing reasons for absence in departments where reason was recorded was small and was similar across employment groups for women, although in men it was slightly higher in the lower employment group. The civil service is at present introducing a comprehensive coding schedule which all departments and payroll centres will use. Civil servants from departments that code reason for absence are unlikely to differ in terms of potential confounders from those departments that do not.

\section{Conclusion}

We report large sex and employment grade differences in the distribution of medical reasons for sickness absence that are similar to differences in morbidity documented in other studies. $^{2-6}$ Possible explanations include the subjective nature of illness and disease; the work/family interface; and the influence of the absence culture.

There was moderate agreement on reason for absence between the civil service and GP for very long spells of absence (>21 days), although little is known about agreement for shorter absences where participants completed their own certificate.

In the Whitehall II study, both men and women within grades were engaged in similar work, so not subject to different occupational exposures. We are at present collecting further information on different aspects of participants' work and home lives, with particular focus on psychosocial factors. This may enable us to explain why those in the lower employment grades experience and report poorer health, as do women after taking account of employment grade. As follow up continues, it will also be possible to examine how sickness absence relates to serious morbidity and mortality.

We thank all participating civil service departments and their welfare, personnel, and establishment officers; the Occupational Health and Safety Agency; the Council of Civil Service Unions; and all participating civil servants. We would like to thank all members of the Whitehall II study team and in particular Alan Harding for computer support, and screening coordinator Julie Harding for compung ulie Moore and Aleks Macheta for data management. Finally, we are particularly indebted to the general practitioners who provided us with further information for this study. The study was supported by grants from the Medical Research Council, Health and Safety Executive, British Heart Foundation, National Heart and Safety Executive, British Heart Foundation, National Heart Lung and Blood Institute (2 RO1 HL36310-04), Agency for
Health Care Policy Research (5 RO1 HS06516), the New EngHealth Care Policy Research (5 RO1 HS06516), the New England Medical Centre-Division of Health Improvement, Institute for Work and Health, Toronto, and The John D and
Catherine T MacArthur Foundation Research Network on Catherine T MacArthur Foundation Research Network on
Successful Midlife Development. Fiona North was supported Successful Midlife Development. Fiona North was supported by the Health Research Council of New Zealand and National
Heart Foundation of New Zealand. MM is supported by a Medical Research Council research professorship.

1 Confederation of British Industry. Managing absence-in sickness and in health. London: CBI, 1997.

2 North F, Syme SL, Feeney A, et al. Explaining socioeconomic differences in sickness absence: the Whitehall II study. BMF 1993;306:361-6.

3 Thompson D. Sickness absence in the civil service. Proceedings of the Royal Society of Medicine 1972;65:572-7.
4 Taylor PH. Occupational and regional associations of death, disablement and sickness absence among Post Office staff 1972-5. Br f Ind Med 1976;33:230-5.

5 Soderfeldt B, Danermark B, Larsson S. Social class and sickness absences. Scand $\mathcal{F}$ Soc Med 1987;15:211-7.

6 Chevalier A, Luce D, Blanc C, Goldberg M. Sickness absence at the French National Electric and Gas Company. $\mathrm{Br}$ F Ind Med 1987;44:101-10.

7 Taylor P. Sickness absence: facts and misconceptions. $f R$ Coll Physicians Lond 1974;8:315-33.

8 Semmence A. Rising sickness absence in Great Britain-a general practitioner's view. Fournal of the Royal College of General Practitioners 1971;21:125-46.

9 Bourbonnais R, Vinet A, Vezina M, Gingras S. Certified sick leave as a non-specific morbidity indicator: a case-referent study among nurses. Br f Ind Med 1992;49:673-8.

10 Kristensen TS. Sickness absence and work strain among Danish slaughterhouse workers: an analysis of absence from work regarded as coping behaviour. Soc Sci Med 1991;32:15-27.

11 Tellnes G, Bjerkedal T. Epidemiology of sickness certification. Scand F Soc Med 1989;17:245-51.

12 Marmot MG, Davey Smith G, Stansfeld S, et al. Health inequalities among British civil servants: the Whitehall II study. Lancet 1991;337:1387-93.

13 World Health Organisation. International classification of disease, 8th revision. Geneva: WHO, 1965.

14 Royal College of General Practitioners. The classification of analysis of general practitioner data. London: RCGP, 1986.

15 Office for National Statistics. Living in Britain. Results from the 1995 general household survey. London: The Stationery Office, 1997.

16 Royal College of General Practitioners, Office of population censuses and surveys, Department of Health and Social Security. Morbidity statistics from general practice 1981-2. London: HMSO, 1986.

17 Haland Haldorsen EM, Brage S, Stromme Johannesen T, et al. Musculoskeletal pain: concepts of disease, illness, and sickness certification in health professionals in Norway. Scand F Rheumatol 1996;25:224-32.

18 Searle SJ. Sickness absence and duration of service in the Post Office 1982-3. Br F Ind Med 1986;43:458-64.

19 Balcombe J, Strange N, Tate G. Wish you were here: how UK and fapanese-owned organisations manage attendance. London: The Industrial Society, 1993.

20 MIND . The MIND survey: stress at work. London: Chambers Cox, 1993.

21 McCormick A, Rosenbaum M. Morbidity statistics from general practice 1981-2. Third national study: socio-economic analyses microfiche. London: HMSO, 1990. (Series MB5 no 2:3-126.)

22 Cox BD, Blaxter M, Buckle AJL, et al. The health and lifestyle survey: preliminary report. Cambridge: Health Promotion Research Trust, 1987

23 North F. Work and absence from work [PhD thesis]. London: University of London, 1990.

24 Verbrugge LM. Gender and health: an update on hypotheses and evidence. F Health Soc Behav 1985;26:156-82.

25 Hibbard JH, Pope CR. Another look at sex differences in the use of medical care: illness orientation and the types of use of medical care: illness orientation and the types of morbidities for

26 Popay J, Bartley M, Owen C. Gender inequalities in health: social position, affective disorders, and minor physical morbidity. Soc Sci Med 1993;36:21-32.

27 Waldron I. Sex differences in illness incidence, prognosis and mortality: issues and evidence. Soc Sci Med 1983;17: 1107-23.

28 MacIntyre S, Hunt K, Sweeting H. Gender differences in health: are things really as simple as they seem? Soc Sci Med 1996:42:617-24.

29 Haynes RB, Sackett DL, Taylor DW, et al. Increased absenteeism from work after detection and labelling of hypertensive patients. N Engl f Med 1978;299:741-4.

30 Martikainen PT. Unemployment and mortality among Finnish men, 1981-5. BMF 1990;301:407-11.

31 Marmot MG, Feeney A, Shipley M, North F, Syme SL. Sickness absence as a measure of health status and functioning: from the UK Whitehall II study. $\mathcal{f}$ Epidemiol Community Health 1995;49:124-30.

32 Office for National Statistics. Mortality statistics, cause 1993 (revised) and 1994. London: HMSO, 1996.

33 Alderson MR. Data on sickness absence in some recent publications of the Ministry of Pensions and National Insurance. Br F Prev Soc Med 1967;21:1-6.

34 Goodwin R. Trends in sickness and invalidity benefit with special reference to mental and stress related causes [abstract]. $1993 ; 1-7$ 